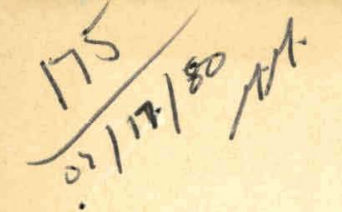

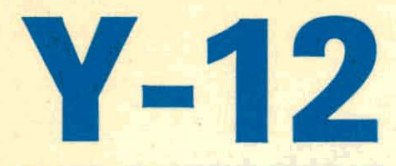

OAK RIDGE

Y-12

PLANT

\section{UNION \\ CARBIDE}

\section{MASTER}

Y-2214

June 1980

OPERATED BY

UNION CARBIDE CORPORATION FOR THE UNITED STATES

DEPARTMENT OF ENERGY
J. R. Ferguson

E. R. Rogers

MASS SPECTROMETER FOR THE ANALYSES OF GASES 


\section{DISCLAIMER}

This report was prepared as an account of work sponsored by an agency of the United States Government. Neither the United States Government nor any agency Thereof, nor any of their employees, makes any warranty, express or implied, or assumes any legal liability or responsibility for the accuracy, completeness, or usefulness of any information, apparatus, product, or process disclosed, or represents that its use would not infringe privately owned rights. Reference herein to any specific commercial product, process, or service by trade name, trademark, manufacturer, or otherwise does not necessarily constitute or imply its endorsement, recommendation, or favoring by the United States Government or any agency thereof. The views and opinions of authors expressed herein do not necessarily state or reflect those of the United States Government or any agency thereof. 


\section{DISCLAIMER}

Portions of this document may be illegible in electronic image products. Images are produced from the best available original document. 
Printed in the United States of America. Available from National Technical Information Service

U.S. Department of Commerce

5285 Port Royal Road, Springfield, Virginia 22161

Price: Printed Copy A02; Microfiche A01

This report was prepared as an account of work sponsored by an agency of the United States Government. Neither the United States Government nor any agency thereof, nor any of their employees, nor any of their contractors, subcontractors, or their employees, makes any warranty, express or implied, nor assumes any legal liability or responsibility for any third party's use or the results of such use of any information, apparatus, product or process disclosed in this report, nor represents that its use by such third party would not infringe privately owned rights. 


\title{
MASS SPECTROMETER FOR THE ANALYSES OF GASES
}

\author{
J. R. Ferguson \\ E. R. Rogers
}

Plant Laboratory Departinent

Y.12 Product Certification Division

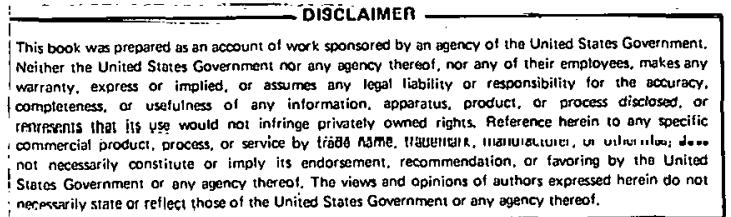

Steites Governmenstitute or imply irs endorsement. recommens alion, ar lavoring by tha United

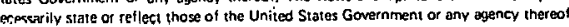

Oak Ridge Y.12 Plant

P. O. Box Y. Oak Ridge, Tennessee 37830

Prepared for the Department of Energy Under US Government Contract W-7405-eng-26 


\section{.
ABSTRACT}

A 6-in.-radius, $60^{\circ}$ magnetic-sector mass spectrometer (designated as the MS-200) has been constructed for the quantitative and qualitative analyses of fixed gases and volatile organics in the concentration range from $1 \mathrm{ppm}$ (by volume) to $100 \%$. A partial pressure of $1 \times 10^{-6}$ torr in the inlet expansion volume is required to achieve a useful signal at an electron-multiplier gain of 10,000 . 


\section{CONTENTS}

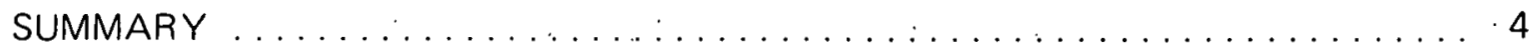

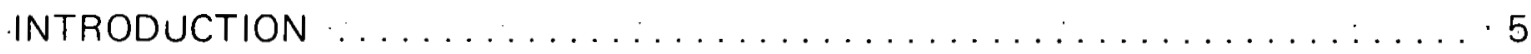

A MASS SPECTROMETER FOR THE ANALYSES OF GASES $\ldots \ldots \ldots \ldots \ldots \ldots \ldots$

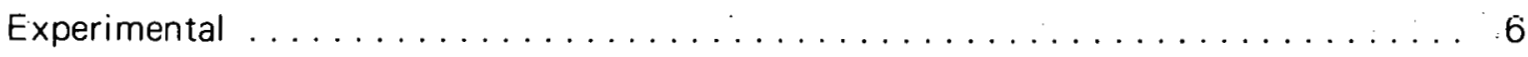

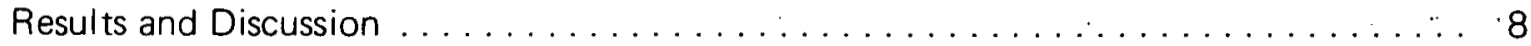

Conclusion .................................. 10

REFERENCES ............................. 11

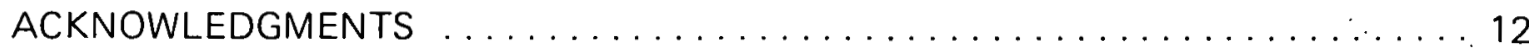




\section{SUMMARY}

A mass spectrometer has been constructed for the quantitative and qualitative analyses of fixed gases and volatile organics. The basic mass spectrometer is a 6 -in.-radius, $60^{\circ}$ magnetic-sector analyzer which has previously $1 ; 2$ been used for thermal-ionization mass spectrometry, both in the ion counting and in the current-integration data acquisition modes.

The mass spectrometer was adapted for gas analysis by the development of a stainless-steel molecular-leak sample entry system and of programmable-ranging data-handling electronics. An electron-impact ionizer without a source magnet is used.

Limits-of-error are .10 to $15 \%$ relative at the $1 \%$ level (depending on the gas species being analyzed), 2 to $10 \%$ at the $10 \%$ level, and 1 to $3 \%$ at higher concentrations. The fragmentation pattern for butane is reproducible to within $3 \%$ of the relative intensities of the peaks.

The ion-source pressure is maintained at approximately $2 \times 10^{-9}$ torr with no sample present, which gives acceptably low backgrounds for the gases of interest.

Sufficient sensitivity is available for parts-per-million analysis. Under normal operating conditions, partial pressures (of approximately $10^{-12}$ torr) of the fixed gases in the source are detectable. Therefore, detection limits are essentially determined by background partial pressures and stability. 


\section{INTRODUCTION}

The Special Samples Mass Spectrometry Laboratory of the Oak Ridge Y-12 Plant(a) is required to analyze a wide variety of samples for both fixed gases and volatile or semivolatile organics. These analyses are in support of $Y-12$ Development Division activities, weapons production, environmental monitoring, and occupational health and safety programs. These analyses are currently being performed on a 6 -in.-radius, $60^{\circ}$ magnetic-sector mass spectrometer whose construction and reconstruction extended back into the 1950s. While this instrument is equal to the task when in peak-operating conditions, maintenance downtime has become intolerable; and peak performance is rarely achieved.

The goal of this projecı was to adapt an existing mass-spectrometer design to the gas analyses needs of the laboratory. The requirements of this instrument are that it perform quantitative and qualitative analyses for both organic and inorganic gases in the concentration range from a few parts per million by volume to $100 \%$. In addition, the instrument must provide for sample entry via expansion volume and molecular leak for large-quantity samples, direct entry for standard leaks, and Toepler pump compression of low-quantity samples. Since the analytical method is the molecular-leak 3 method, linearity of mass-spectrometer response with expansion-volume pressure is a stringent requirement. This condition is met by the use of $12.5-\mu$ m-diameter apertures in the molecular leak. By using the convention that molecular flow will be maintained if the mean free path of the gas molecules in the expansion volume is 20 times the hole diameter, 4 the molecular flow would be maintained at pressures below $200 \mu \mathrm{m}\left(2 \times 10^{-1}\right.$ torr $)$ in the expansion volume. Some falloff from linearity may be expected at pressures exceeding this limit.

The molecular-leak sample entry system is all stainless steel and pumped by a diffusion pump with a liquid nitrogen trap to reduce background readings. The electronics have included a programmable-ranging amplifier with a strip-chart-recorder readout. A Hall probe is incorporated into the magnet gap and this field-strength reading is used in a negative-feedback circuit for magnet control and to a gaussmeter for determining mass $(\mathrm{M} / \mathrm{Z})$ location.

(a) Operated by the Union Carbide Corporation, Nuclear Division, for the Department of Energy. 


\section{A MASS SPECTROMETER FOR THE ANALYSES OF GASES}

\section{EXPERIMENTAL}

The analytical technique used in the Special Samples Mass Spectrometry Laboratory for gas analysis can be summarized by the phrase "molecular-leak sample-introduction mass spectrometry". 3,4 In this method, the gaseous sample is introduced into an expansion volume by a sequence of valves. While maintaining viscous flow, the relative concentrations of the components of a mixture are retained from the sample container into the expansion volume. The expansion volume is kept at high vacuum prior to sample introduction. The pressure in the expansion volume is read with a metal-diaphragm differential pressure gauge which is gas-species independent.

The expansion volume is connected to the mass-spectrometer ion source through a molecular leak: an aperture which has a small diameter, $d$, compared to the mean free path, $\lambda$, of the gas molecules, i.e.,

$$
d \leqslant \frac{\lambda}{20}
$$

Since the flow through the leak for a given gas of molecular weight, $M$, is inversely proportional to $M^{1 / 2}$ and the speed with which the gas is pumped out of the source is also inversely proportional to $\mathrm{M}^{1 / 2}$, then these two mass effects are compensating; and the relative concentrations in the ion source of a mixture are the same as in the expansion volume, i.e., the sample itself-as long as molecular flow through the leak is maintained. 4

The ionization efficiency of the electron-impact-ionization source does differ for different gases; therefore, the method does require calibration of the instrument by determining the signal strength versus the expansion-volume partial pressure for each gas to be analyzed. When this response is linear, i.e., in the molecular-flow pressure range, the partial pressures of each gas in a mixture can be determined; and the volume percent concentrations can be computed.

The analyzer is a $60^{\circ}$ ( $\pi / 3$-radian)-magnetic-sector, 6-in. (152.4-mm)-radius mass spectrometer. It has been designed to use sexless flanges that incorporate metal sealing gaskets which enable an ultimate-system vacuum of $<2 \times 10^{-9}$ torr. The source region is evacuated with a 3 -in. diffusion pump charged with a polyphenyl ether oil. The pump has a pumping rate of $285 \mathrm{~L} / \mathrm{s}$ and is backed with a 100-L/min mechanical pump. A liquid nitrogen trap is used above the diffusion pump to produce a lower background for certain gases. An isolation valve is provided between the flight tube and the "pump stack" to enable more rapid recovery to high vacuum following the letdown of the flight tube to atmospheric pressure for maintenance.

The receiver section, which includes the entire flight tube from immediately below the source baseplate, is evacuated with a $270-\mathrm{L} / \mathrm{s}$ getter-ion pump. An isolation valve is also provided between this pump and the flight tube. The flight tube is divided into two, 
separate, pumping sections by a 0.003 -in. slit located on the source baseplate. This slit is also the final-defining slit for the ion beam.

The beam intensities are detected and amplified by means of a 14-stage electron multiplier which is set for a gain of approximately 10,000. An electrometer is used to convert the current output of the multiplier to a voltage suitable for amplification. The electrometer is mounted in close proximity to the flight tube to improve the signal-to-noise ratio at low ion-beam currents. The electrometer is a linear current amplifier. The output voltage $\left(V_{0}\right)$ is proportional to the input current (I) times the feedback resistor $\left(R_{f}\right)$;

$$
V_{0}=-1 \times R_{f}
$$

The feedback resistor is operator selectable (to either $10^{8}$ or $10^{9}$ ohms) from the console by pressing a button. The output of the electrometer is scaled by a programmable-amplifier module and is displayed simultaneously on a strip-chart recorder and an analog meter. lon-beam currents typically are in the range from $10^{-11}$ to $10^{-16} \mathrm{~A}$ and can be accommodated by the dynamic range of the amplifier system. The programmable amplifier is a four-wide NIM bin (b) module that has been designed to operate in conjunction with the magnet-control module to enable automatic range changing when selecting masses. When a mass is selected (any one of seven reference peaks) and the range-of-amplification is chosen, the gain setting can be stored in a scratch-pad memory-so that at any future time when the same reference peak is chosen, the range is automatically returned to the stored setting. If the programmed range is unsuitable, it can be changed at the push of a button.

The magnet supply is of solid-state modular construction and is designed to operate as a stand-alone unit with self-contained scan circuitry or as a slave unit. The slave mode is used in the MS-200 gas mass spectrometer. The magnet-current supply receives a reference signal from the magnet-control module to set the magnitude of the magnet flux. The magnet supply is of the high-voltage low-current type which is compatible with magnets in use within the Y-12 Plant Laboratory. The magnet itself is constructed of high-purity iron, machined to conform to the radius of the flight tube to yield a more concentrated field while reducing fringing effects. A Hall-effect probe is inserted into the magnet pole gap to monitor the intensity of the field while producing a feedback signal that is used in a servoloop to enable a return to a specific gauss setting (therefore, a specific mass setting). The output of the gaussmeter is also electronically squared and is used as a direct digital readout of the mass location.

A magnet-control module is used in conjunction with the magnet supply and guassmeter and gives the operator the ability to preset the location of seven reference masses and then, at the press of a button, to cause the magnet to "peak jump" from one mass location to another. The scan functions (scan up and scan down) are also push-button controlled with a "zoom" "feature for rapid scan.

(b) Nuclear Instrument Modules (NIM) standard triple-wide module per Document TID-20893. 


\section{RESULTS AND DISCUSSION}

The mass spectrometer has been tested to define: (1) the baseline performance characteristics, such as: resolution, sensitivity, source quiescent pressure, and peak location or $M / Z$ reproducibility; and (2) the analytical performance characteristics, such as: detection limits, background partial pressures, quantitative precision, qualitative reliability, and reproducibility of organic-fragmentation patterns.

The ion source was equipped with a 0.003 -in. slit, and the receiver slit was set to give approximately $95 \%$ beam transmission to the electron multiplier. Under those conditions, the resolution was determined to be approximately 420 at $5 \%$ peak height, as measured at $M / Z=4$ and $M / Z=131$. All subsequent performance data were taken under these conditions.

The sensitivity for nitrogen and helium is on the order of $5 \times 10^{-5} \mathrm{~A} /$ torr or $5 \times 10^{-5} \mathrm{~A}$ of ion current incident on the first dynode of the electron multiplier per torr of partial pressure in the ion source. To relate this value to an analytical detection limit, assume a multiplier gain of $10^{4}$ and an electrometer feedback resistance of $10^{8} \mathrm{ohms}$. The sensitivity would be expressed as $5 \times 10^{7} \mathrm{~V}$ of signal per torr of partial pressure in the source. If $50 \mu \mathrm{V}$ or $5 \times 10^{-5} \mathrm{~V}$ is the smallest signal which is significant, then the detection limit in the source is:

$$
\frac{\left(5 \times 10^{-5}\right) \mathrm{V}}{5 \times 10^{7} \mathrm{~V} / \text { torr }} \text { or } 1 \times 10^{-12} \text { torr partial pressure in the source. }
$$

The partial pressure of a gas in the source is equal to the background (quiescent partial pressure) plus the amount of that gas coming from the expansion volume. Since the source partial pressure is approximately $10^{-6}$ of the expansion-volume partial pressure, the detection limit should be approximately $1 \times 10^{-6}$ torr in the expansion volume or $1 \mathrm{ppm}$ divided by the total pressure of the gas in the expansion volume expressed in torr. For example; at a pressure of 0.1 torr, the analytical detection limit should be $10 \mathrm{ppm}$ if no background is present, $5 \mathrm{ppm}$ at 0.2 torr, and $1 \mathrm{ppm}$ at 1.0 torr. Background is always present and is dramatically different for each gas. To demonstrate, hydrogen, methane $\left(\mathrm{CH}_{4}\right)$, and argon were measured at the 10-ppm level with an expansion-volume pressure of 0.235 torr. By computing the detection limit based to the standard deviation of 10 measurements, the effect of a high and variable hydrogen background is shown in Table 1.

Table 1

These results reflect the fact that the hydrogen quiescent partial pressure is on the order of $5 \times 10^{-10}$ torr or more than 100 times the sensitivity limit.

Factors affecting quantitative analysis are reproducibility of organic-fragmentation

\begin{tabular}{lccc}
\multicolumn{2}{c}{ Table 1} \\
DETECTION LIMITS FOR SELECTED GASES \\
\hline Gas & $\mathrm{M} / \mathrm{Z}$ & $\begin{array}{c}\text { Pressure } \\
\text { (torr) }\end{array}$ & $\begin{array}{c}\text { Detection } \\
\text { Limit (1) } \\
\text { (ppm) }\end{array}$ \\
\hline Argon & 40 & 0.235 & 6.1 \\
Methane & 15 & 0.235 & 5.6 \\
Hydrogen & 2 & 0.235 & 272 \\
\hline
\end{tabular}

(1) Based on three standard deviations of 10-ppm standard. 
patterns, linearity of signal strength with expansion-volume pressure and day-to-day sensitivity variation. Table 2 shows the reproducibility of the $n$-butane $\left(\mathrm{C}_{4} \mathrm{H}_{10}\right)$ fragmentation pattern on 12 measurements made on 4 different days over a 1-week period.

The deviations from linearity of signal versus pressure for $n$-butane, carbon dioxide $\left(\mathrm{CO}_{2}\right)$, and helium over the range of 0.001 to 0.2 torr were all less than $5 \%$ relative, which is considered adequate for quantitative work.
Table 2

REPRODUCIBILITY OF $n$-BUTANE FRAGMENTATION PATTERNS

\begin{tabular}{|c|c|c|c|c|}
\hline$M / Z$ & $\begin{array}{l}\text { Relative } \\
\text { Intensity }\end{array}$ & $\begin{array}{l}\text { Standard } \\
\text { Deviation }\end{array}$ & $\begin{array}{c}\text { Relative } \\
\text { Standard } \\
\text { Deviation } \\
(\%)\end{array}$ & $\begin{array}{c}\text { Number } \\
\text { of } \\
\text { Measurements }\end{array}$ \\
\hline 43 & 100 & . & - & 12 \\
\hline 29 & 52.11 & 0.33 & 0.64 & 12 \\
\hline 27 & 33.26 & 0.26 & 0.79 & 12 \\
\hline 28 & 38.12 & 0.61 & 1.61 & 12 \\
\hline 41 & 28.76 & 0.17 & 0.61 & 12 \\
\hline 39 & 7.75 & 0.09 & 1.16 & 12 \\
\hline 58 & 9.58 & 0.46 & 4.77 & 12 \\
\hline 42 & 13.30 & 0.12 & 0.90 & 12 \\
\hline 26 & 4.14 & 0.01 & 0.93 & 12 \\
\hline 15 & 2.13 & 0,04 & 1.81 & 12 \\
\hline
\end{tabular}

The relative sensitivity factors for six gases were determined each day over a period of 2 weeks, and the reproducibilities are shown in Table 3.

Table 3

REPRODUCIBILITY OF RELATIVE SENSITIVITY FACTORS

\begin{tabular}{lccccc}
\hline & $\begin{array}{c}\text { Relative } \\
\text { Sensitivity } \\
\text { Factor } \\
\text { (arbitrary } \\
\text { units) }\end{array}$ & $\begin{array}{c}\text { Standard } \\
\text { Deviation }\end{array}$ & $\begin{array}{c}\text { Relative } \\
\text { Standard } \\
\text { Deviation } \\
(\%)\end{array}$ & M/Z & $\begin{array}{c}\text { Number } \\
\text { of } \\
\text { Measurements }\end{array}$ \\
\hline Helium & 2493.5 & 58.9 & 2.4 & 4 & 7 \\
Argon & 3664.7 & 41.4 & 1.1 & 40 & 5 \\
Carbon Dioxide & 3577.0 & 6.9 & 0.2 & 44 & 5 \\
Methane & 5431.3 & 97.7 & 1.8 & 16 & 5 \\
Methane & 4687.2 & 121.1 & 2.6 & 15 & 7 \\
Nitrogen & 4860.6 & 41.2 & 0.8 & 28 & 5 \\
\hline
\end{tabular}

The quantitative precision and accuracy was determined on three standard mixes and the results are shown in Tables 4 through 6 . These analyses were repeatedly done over a period of approximately 3 weeks.

Table 4

PRECISION AND ACCURACY ON GAS MIXTURE 1

\begin{tabular}{lccccr}
\hline \multicolumn{1}{c}{ Gas } & $\begin{array}{c}\text { Average } \\
\text { Concentration } \\
\text { (vol \%) }\end{array}$ & $\begin{array}{c}\text { Standard } \\
\text { Deviation }\end{array}$ & $\begin{array}{c}\text { Relative } \\
\text { Standard } \\
\text { Deviation } \\
(\%)\end{array}$ & $\begin{array}{c}\text { Number } \\
\text { of } \\
\text { Measurements }\end{array}$ & Expected \\
\hline Hydrogen & 1.10 & 0.053 & 4.8 & 12 & 1.03 \\
Helium & 93.93 & 0.303 & 0.32 & 12 & 93.96 \\
Methane & 0.98 & 0.054 & 5.49 & 12 & 0.95 \\
Carbon Monoxide + Nitrogen & 2.03 & 0.122 & 6.00 & 12 & 2.03 \\
Argon & 0.92 & 0.067 & 7.30 & 12 & 1.02 \\
Carbon Dioxide & 1.04 & 0.090 & 8.63 & 12 & 1.01 \\
\hline
\end{tabular}


Table 5

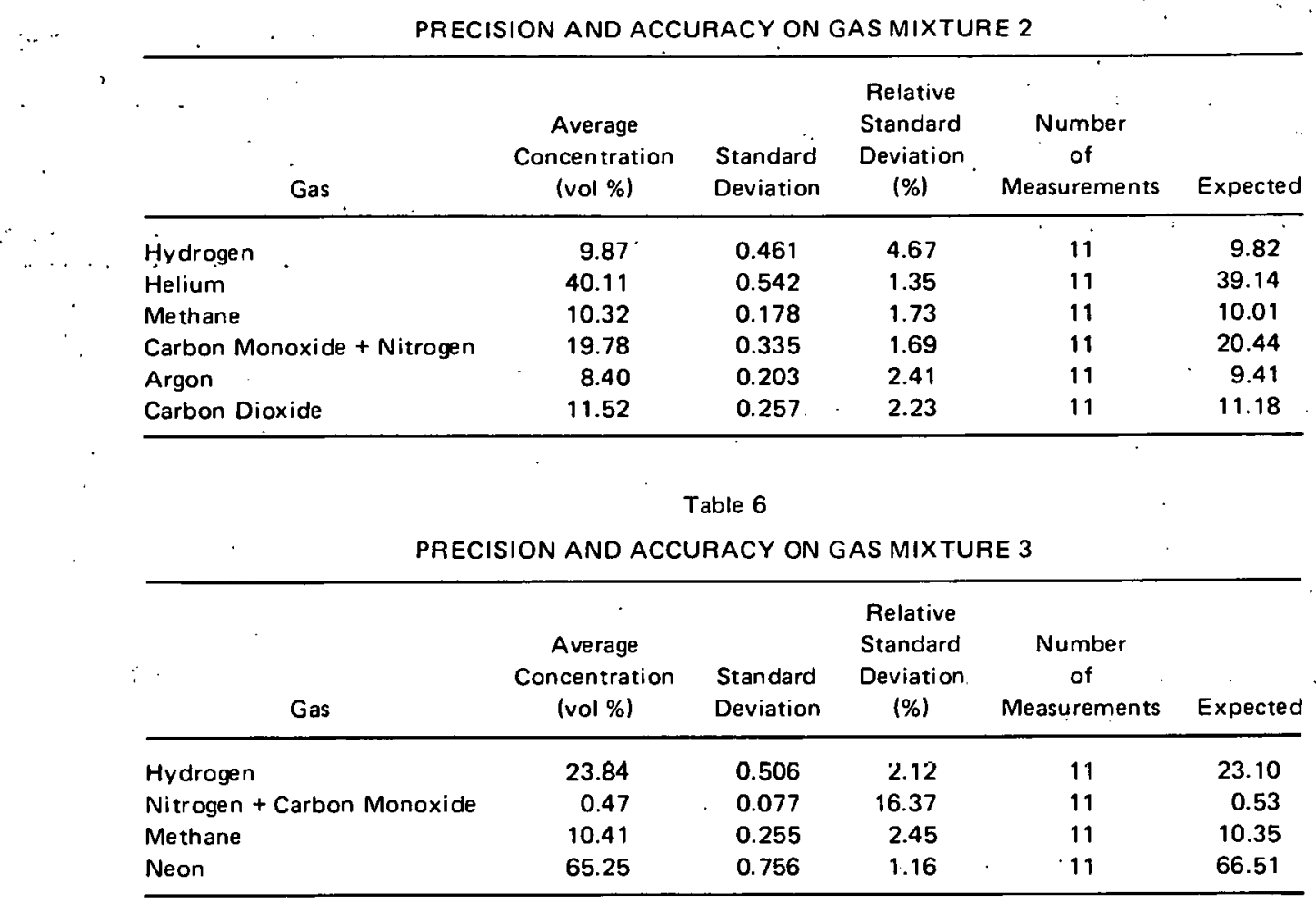

The MS-200 has been found to provide quantitative results over a wide range of concentrations and gas species including some highly polar organic vapors. Some difficulty has been encountered in achieving reproducible results for trace oxygen analysis. Sensitivity for oxygen appears to fluctuate with immediate prior history of the sample entry system. Organic samples tend to increase the sensitivity, and inorganics tend to decrease the sensitivity. This is, obviously, a surface effect associated with the stainless steel tubing. Alternative methods do exist for trace oxygen.

\section{CONCLUSION}

The MS-200 Mass Spectrometer has been found to meet the stated goals of the project. The instrument has been installed in the Special Samples Mass Spectrometry Laboratory and has been in use for more than 3 months. The results achieved during the initial checkout have been routinely achieved without difficulty by laboratory personnel. Additional efforts which might be beneficial include an automatic data-handling system and a more uniformly heated sample entry system. Materials other than stainless steel could be investigated for a sample entry system. 


\section{REFERENCES}

1. J. R. Ferguson, J. D. Caylor, E. R. Rogers, and S. H. Cole, Rapid Determination of Uranium in Natural Waters by Thermal Emission Mass Spectrometry; Union Carbide Corporation, Nuclear Division, Oak Ridge Y-12 Plant, Oak Ridge, Tenn., Y-2073 (1977).

2. W. T. McBryde, E. R. Rogers, and J. R. Ferguson, A Thermal Emission Mass Spectrometer for Rapid and Accurate Determination of Uranium Isotopes; Union Carbide Corporation, Nuclear Division, Oak Ridge Y-12 Plant, Oak Ridge, Tenn., Y-2127 (1978).

3. B. J. Millard, Quantitative Mass Spectrometry (Heyden \& Son, London, 1978).

4. R. W. Kiser, Introduction to Mass Spectrometry and Its Applications (Prentice-Hall, Inc., Englewood Cliffs, Calif., 1965). 


\section{ACKNOWLEDGMENTS}

The authors would like to acknowledge the contributions by members of the $\mathrm{Y}-12$ Plant Laboratory to this project. J. L. Heatherly and M. B. Rollins acquired most of the quantitative data used in initial checkout of the MS-200. M. G. Davis has done a superior job in the postinstallation checkout area on a wide range of very demanding samples. W. T. McBryde was a source of consultation and support throughout this project. 


\section{Distribution}

Allied Chemical Corporation

Echo, W.

Filby, E. E.

Department of Energy - Oak Ridge

Butts, V. V.

Hickman, H. D.

Poteat, R. M.

Department of Energy - Grand Junction .

Hannon, S. S.

Goodyear Atomic Corporation

Vita; O. A.

Lawrence Livermore National Laboratory

Arnold, W. F.

Tinney, J. F.

Los Alamos National Scientific Laboratory

Abcrnathy, R. M.

Hoyt, H. C.

Sharp, R. R.

Waterbury, G. R.

Monsanto-Mound Facility.

Rodenburg, W: W.

New Brunswick Laboratory

Bingham, C. D.

Oak Ridge Gaseous Diffusion Plant

Arendt, J. W.

Armstrong, R. C.

Levin, R. W.

Morrow, R. W.

Smith, L. A.

Stief, S. S.

Wilcox, W. J., Jr

Oak Ridge National Laboratory

Carter, J. A.

Hopkins, C. C.

Shults, W. D.

Walker, R. L. 
Oak Ridge Y-12 Plant

Alvey, H. E.

Andrew, R. E.

Bernander, N. K.

Bright, G. R.

Briscoe, O.W.

Burditt, R. B.

Cagle, G. W.

Cole, S. H.

Davis, M. G.

Dodson, W. H./Googin, J. M.

Dorsey, J. G.

Duggan, H. G.

Ferguson, J. E.

Ferguson, J. R. (10)

Foulk, D. L.

Franklin, J. C.

Fraser, R. J.

Futrell, T. L.

Harman, W. D.

Heatherly, J. L.

Jackson, V. C.

Jones, F. W.

Kahl, K. G.

Keith, A.

Kent, R. H.

King, H. G., Jr

Kitc, $H: T$.

McBryde, W. T.

McLendon, J. D.

Mills, J. M., Jr

Powell, G. L.

Rhew, J. E.

Rice, W. W.

Rogers, E. R. (10)

Rutenberg, A. C.

Schneider, P. G.

Schreyer, J. M.

Smith, H. F., Jr

Smith, R. D.

Stoner, H. H.

Tewes, W. E.

White, J. C.

Y-12 Central Files (master copy)

$Y-12$ Central Files (route copy)

$Y-12$ Central Files $(Y-12 R C)$

$Y-12$ Central Files (5)
Paducah Gaseous Diffusion Plant

Bewley, H. D.

Katzel, V. G.

Rockwell International - Rocky Flats :

Carpenter, R. L.

Sandia National Laboratories.- Livermore

Spencer, W. J.

Savannah River Laboratory

Belew, W. L.

Folger, R: L.

Union Carbide Corporation - New York

Tinsley, S.W.

In addition, this report is distributed in accordance with the Category UC-37, Instruments, as given in the Standard Distribution for Unclassified Scientific and Technical Reports, DOE/TIC-4500. 